\title{
Liquid Chromatographic Separation and Determination of Aromatic Sulfonates in an Aquatic Environment Using a Photodiode Array and Electrospray Ionization-Mass Spectrometer as Detectors
}

\author{
R. Nageswara Rao, ${ }^{\dagger}$ N. VenKateSwarlu, Sara Khalid, and R. NARASimha \\ HPLC Group, Division of Analytical Chemistry, Discovery Laboratory, Indian Institute of Chemical Technology, \\ Tarnaka, Hyderabad-500 007, India
}

\begin{abstract}
A simple and rapid method involving high-performance liquid chromatographic separation, followed by photodiode array (PDA) and electrospray ionization-mass spectrometric (ESI-MS) detection of aromatic sulfonates in waste-water effluents of industrial units producing optical whitening agents, has been developed. The separation was achieved on a reversedphase Hypersil $\mathrm{C}_{18}$ column using gradient elution of a mobile phase consisting of $0.05 \mathrm{M}$ ammonium formate-methanol with decreasing concentration of the buffer at room temperature. The minimum detection limits were determined to be in the range of $0.2-1.8 \times 10^{-9} \mathrm{~g}$ using PDA and ESI-MS detectors.
\end{abstract}

(Received November 20, 2002; Accepted December 24, 2002)

\begin{abstract}
Aromatic sulfonates, such as the benzene and stilbene derivatives, are widely used in a variety of industrial processes. ${ }^{1}$ Benzene sulfonates are used as intermediates in the production of ion-exchange resins, pesticides and wetting agents, while stilbene sulfonic acids are used as intermediates in the preparation of optical brighteners and synthetic dyes. Although these compounds have been produced and used for a long time, little information is known about their toxicology and ecotoxicology. Further, these compounds are highly soluble in water, and are not easily degradable in environmental biological systems. ${ }^{2}$ These are highly persistent and accumulate in natural ground and surface water, causing environmental problems, which, in turn, call for efficient procedures for the separation and determination of a broad range of compounds in aquatic environment. ${ }^{3,4}$
\end{abstract}

A variety of chromatographic and electrophoretic techniques have been applied for the analysis of aromatic benzene and stilbene sulfonates in different sample matrices. ${ }^{5,6}$ Gas chromatography (GC) has limited applications because of the non-volatility of these compounds. Derivatization to their trimethylsilyl, methyl esters and thionyl chlorides were reported. ${ }^{7,8}$ However, these methods are not suitable when polar functional groups, such as hydroxyl and amino, are attached to the aromatic rings. For this reason, the liquid-chromatographic and electrophoretic methods are preferred to GC. Recently, capillary zone electrophoresis (CZE) with UV and fluorescence detectors has been used extensively. ${ }^{9}$ Cugat et al. have reviewed a large number of electrophoretic methods for the determination of benzene and naphthalene sulfonates in water. ${ }^{10}$ Anion exchange and ion-pair reversed-phase high-performance liquid chromatography (RP-HPLC) are the most generally used techniques for the analysis of these compounds. ${ }^{11-13}$ Numerous LC methods with different detection systems, such as UV, fluorescence and particle beam electron impact mass spectrometry, have been reported in the literature. ${ }^{14,15}$ Although

† To whom correspondence should be addressed.
LC-MS is the technique of choice, isomers of the most polar sulfonic acids are not well separated in the buffers used as mobile solvents. The most widely used approach of ion-pair reversed-phase liquid chromatography suffers from a nonvolatility of tetraalkylammonium salts, which contaminate the ESI/APCI interfaces and, consequently, precludes the use of LC-MS as a tool for this purpose. Several alternatives to the use of non-volatile ion-pairing agents have been reported. ${ }^{16,17}$ The use of aqueous ammonium acetate buffers as ion-pairing electrolytes for thermo-spray LC-MS of aromatic sulfonates has been well studied. ${ }^{18}$ However, ammonium acetate is too weak an ion-pairing agent for RP-HPLC, and its use has therefore been restricted to only a limited number of compounds. Recently, formate volatile ion-pairing agents seem to be gaining more importance as an alternative to ammonium acetate. However, as of today, no LC-MS methods involving the use of volatile ion-pairing reagents for the simultaneous determination of benzene and stilbene sulfonates in an aqueous environment are available in the literature. In the present paper we describe the simultaneous separation and determination of benzene and stilbene sulfonic acids by liquid chromatography-photodiode array (LC-PDA) detection, followed by electrospray mass spectrometry (ESI-MS) in the negative-ion mode using the gradient elution of ammonium formate-methanol as a mobile phase.

\section{Experimental}

\section{Materials and reagents}

Ammonium formate (analytical reagent grade) (SD. Fine Chem., Mumbai, India) and HPLC-grade methanol (Spectrochem pvt. Ltd., Mumbai, India) were used. Sulfonic acids viz., metaphenylenediamine-4-sulfonic acid (MPDSA), 3 aminoacetanilide-4-sulfonic acid (AASA), $p$-phenylenediamine-2-sulfonic acid (PPDSA), p-phenylenediamine-2,6disulfonic acid (PPDDSA), $p$-phenylenediamine-2-sulfonic 


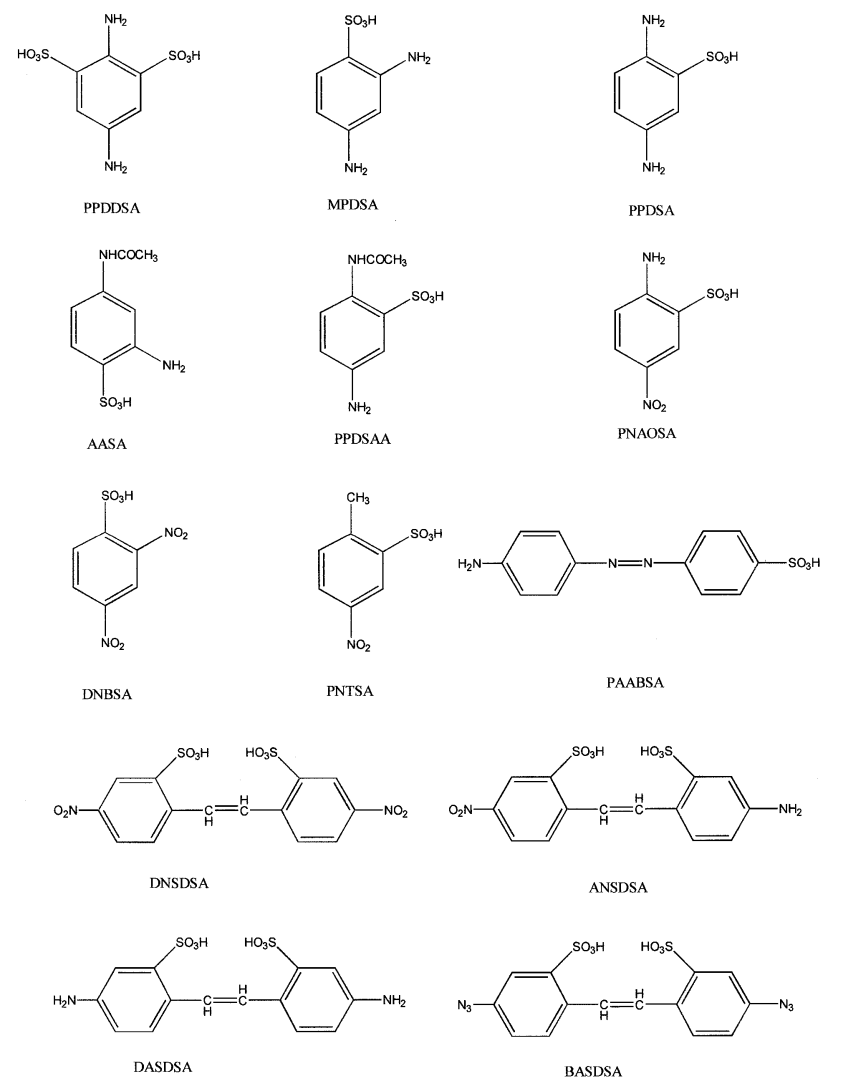

Fig. 1 Chemical structures of benzene and stilbene sulfonic acids studied in the present investigation.

acid-acetyl (PPDSAA), $\quad p$-nitroaniline $o$-sulfonic acid (PNAOSA), $p$-nitrotoluene sulfonic acid (PNTSA), 4,4'diaminostilbene-2,2'-disulfonic acid (DASDSA), 4,4'dinitrostilbene-2,2'-disulfonic acid (DNSDSA), 2,4dinitrobenzene sulfonic acid (DNBSA), $p$-aminoazobenzene sulfonic acid (PAABSA), 4-amino-4'-nitrostilbene-2,2'disulfonic acid (ANSDSA) and bis(azidostilbene)disulfonic acid (BASDSA) were a kind gift from $\mathrm{M} / \mathrm{s}$ Orchem and $\mathrm{M} / \mathrm{s}$ Vasant Chemicals Limited, Hyderabad, India.

Glass-distilled water was deionized using a Nanopure II D 3700 cartridge (Nanopure, Barnsted, MA, USA).

\section{Apparatus}

The HPLC system was composed of two LC-10AT VP pumps, an SPD-M10AVP diode array detector, an SIL-10AD VP auto injector, a DGU-12A degasser and an SCL-10A VP system controller (all from Shimadzu, Kyoto, Japan). A reversed-phase Hypersil BDS $\mathrm{C}_{18}$ column $(250 \times 4.6 \mathrm{~mm}$ i.d., 5 $\mu \mathrm{m}$ particle size) (Thermo Quest, Hypersil, Runcorn, UK) was used for separation. The chromatographic and integrated data were recorded using an HP-Vectra (Hewlett Packard, Waldronn, Germany) computer system. A mass spectrometer (Quatro LC, Micromass, UK) coupled with HPLC (Hewlett Packard, Palo Alto, CA, USA) was used for LC-ESI-MS studies.

\section{$L C-P D A$}

The mobile phase, consisting of methanol- $0.05 \mathrm{M}$ ammonium formate, was initially programmed to elute $100 \% 0.05 \mathrm{M}$ ammonium formate up to $4 \mathrm{~min}$, followed by a linear gradient of $60 \%$ methanol within 25 min and back to $100 \%$ buffer within
Table 1 Molecular formulae, abbreviations and CAS numbers of test compounds

\begin{tabular}{clll}
\hline No. & Compound & Molecular formula & \multicolumn{1}{c}{ CAS No. } \\
\hline 1 & PPDDSA & $\mathrm{C}_{6} \mathrm{H}_{8} \mathrm{~N}_{2} \mathrm{O}_{6} \mathrm{~S}_{2}$ & $6409-48-9$ \\
2 & MPDSA & $\mathrm{C}_{6} \mathrm{H}_{8} \mathrm{~N}_{2} \mathrm{O}_{3} \mathrm{~S}$ & $88-63-1$ \\
3 & PPDSA & $\mathrm{C}_{6} \mathrm{H}_{8} \mathrm{~N}_{2} \mathrm{O}_{3} \mathrm{~S}$ & $88-45-9$ \\
4 & AASA & $\mathrm{C}_{8} \mathrm{H}_{10} \mathrm{~N}_{2} \mathrm{O}_{4} \mathrm{~S}$ & $88-64-2$ \\
5 & PPDSAA & $\mathrm{C}_{8} \mathrm{H}_{10} \mathrm{~N}_{2} \mathrm{O}_{4} \mathrm{~S}$ & $6973-05-3$ \\
6 & DASDSA & $\mathrm{C}_{14} \mathrm{H}_{14} \mathrm{~N}_{2} \mathrm{O}_{6} \mathrm{~S}_{2}$ & $81-11-8$ \\
7 & PNAOSA & $\mathrm{C}_{6} \mathrm{H}_{6} \mathrm{~N}_{2} \mathrm{O}_{5} \mathrm{~S}$ & $95-75-3$ \\
8 & DNBSA & $\mathrm{C}_{6} \mathrm{H}_{4} \mathrm{~N}_{2} \mathrm{O}_{7} \mathrm{~S}$ & $89-02-1$ \\
9 & ANSDSA & $\mathrm{C}_{14} \mathrm{H}_{12} \mathrm{~N}_{2} \mathrm{O}_{8} \mathrm{~S}_{2}$ & $119-72-2$ \\
10 & PNTSA & $\mathrm{C}_{7} \mathrm{H}_{7} \mathrm{NO}_{5} \mathrm{~S}$ & $121-03-9$ \\
11 & PAABSA & $\mathrm{C}_{12} \mathrm{H}_{11} \mathrm{~N}_{3} \mathrm{O}_{3} \mathrm{~S}$ & $104-23-4$ \\
12 & DNSDSA & $\mathrm{C}_{14} \mathrm{H}_{10} \mathrm{~N}_{2} \mathrm{O}_{10} \mathrm{~S}_{2}$ & $128-42-7$ \\
13 & BASDSA & $\mathrm{C}_{14} \mathrm{H}_{10} \mathrm{~N}_{6} \mathrm{O}_{6} \mathrm{~S}_{2}$ & $15874-22-3$ \\
\hline
\end{tabular}

$30 \mathrm{~min}$. The mobile phase was filtered through a $0.45-\mu \mathrm{m}$ PTFE filter and degassed using a vacuum before delivering into the system. The analysis was carried out using a reversed-phase Hypersil BDS $\mathrm{C}_{18}$ column $(250 \times 4.6 \mathrm{~mm}$ i.d., $5 \mu \mathrm{m})$ and a flow rate of $1.0 \mathrm{~mL} / \mathrm{min}$ at room temperature $\left(28^{\circ} \mathrm{C}\right)$. Chromatograms were recorded at $254 \mathrm{~nm}$ using an SPD-M10A VP diode array detector.

\section{$L C-E S I-M S$}

LC-ESI-MS analyses were performed with an HP Series 1100 liquid chromatograph (Hewlett Packard, Palo Alto, CA, USA) and a Micromass Quatro LC mass spectrometer equipped with electrospray (ESI) and atmosperic pressure chemical ionization (APCI) interfaces. The chromatographic separation was carried out with Hypersil $\mathrm{C}_{18}$ reversed-phase column and gradient elution with ammonium formate-methanol as the mobile phase at a $1 \mathrm{~mL} / \mathrm{min}$ flow rate. Analyses were performed with an ESI interfacing technique in the negative-ion mode of operation throughout all of the experiments. Nitrogen was used as a nebulizer and dissolution gas. The operating parameters were: nebulizer gas flow, $0.9 \mathrm{~L} / \mathrm{min}$; dissolution gas flow, $9.8 \mathrm{~L} / \mathrm{min}$; nebulizer pressure, $50 \mathrm{psi}$; capillary voltage, $3.0 \mathrm{kV}$; cone voltage, $25 \mathrm{~V}$; source block temperature, $80^{\circ} \mathrm{C}$; disolvation temperature, $20^{\circ} \mathrm{C}$; and ion energy, $2.0 \mathrm{~V}$. MS measurements were performed in the full-scan mode over the mass range of $\mathrm{m} / \mathrm{z} 50$ to 1000 with $0.21 \mathrm{scans} / \mathrm{s}$.

\section{Analytical procedure}

Standards of benzene and stilbene sulfonates $(50 \mu \mathrm{g}$ each $/ \mathrm{ml})$ were dissolved in the mobile phase, and a $20 \mu \mathrm{L}$ volume of each sample was injected and chromatographed under the above conditions. Synthetic mixtures and waste-water effluents were analyzed under identical conditions. The peaks were identified by comparing not only with the retention times of the standards but also the fragmentation patterns obtained by ESI-MS. Solutions containing each analyte in the range of $0.05-25 \mathrm{mg} / \mathrm{L}$ were prepared and used for linearity, LOD and LOQ determinations.

\section{Results and Discussion}

Figure 1 shows the chemical structures of the benzene and stilbene sulfonates studied in the present investigation. The compound abbreviations, molecular formulae and CAS numbers are recorded in Table 1. These substances belong to a family of 
Table 2 Optimized time program for the gradient elution of test compounds by LC

\begin{tabular}{ccc}
\hline Time $/$ min & Ammonium formate, $\%$ & Methanol, $\%$ \\
\hline 0 & 100 & 0 \\
4 & 100 & 0 \\
25 & 40 & 60 \\
30 & 100 & 0 \\
\hline
\end{tabular}

Table 3 Retention data

\begin{tabular}{ccccc}
\hline $\begin{array}{c}\text { Compound } \\
\text { No. }\end{array}$ & $\begin{array}{c}\text { Retention } \\
\text { time/min }\end{array}$ & $\begin{array}{c}\text { Capacity } \\
\text { factor }\left(k^{\prime}\right)\end{array}$ & $\begin{array}{c}\text { Relative } \\
\text { response } \\
\text { factor } \\
(\text { RRF })\end{array}$ & $\begin{array}{c}\text { Wavelength of } \\
\text { maximum } \\
\text { absorption } \\
\left(\lambda_{\max }\right) / \mathrm{nm}\end{array}$ \\
\hline 1 & 2.60 & 1.19 & 2.64 & 219 \\
2 & 3.08 & 1.62 & 3.90 & 227 \\
3 & 3.40 & 1.92 & 3.45 & 245 \\
4 & 8.15 & 4.61 & 4.53 & 227 \\
5 & 9.37 & 5.49 & 3.66 & 257 \\
6 & 10.64 & 7.28 & 1.00 & 338 \\
7 & 12.50 & 9.80 & 1.15 & 368 \\
8 & 15.44 & 12.55 & 3.28 & 254 \\
9 & 15.60 & 13.02 & 2.26 & 219 \\
10 & 18.24 & 15.06 & 1.20 & 275 \\
11 & 20.25 & 16.81 & 1.75 & 222 \\
12 & 21.05 & 17.17 & 1.16 & 352 \\
13 & 22.34 & 18.84 & 1.14 & 335 \\
\hline
\end{tabular}

optical brighteners, which show not only a widespread use in organic chemistry, but also important applications for environmental and toxicological purposes. A Hypersil BDS $\mathrm{C}_{18}$ analytical column was used for the chromatographic separation of all thirteen compounds using a gradient elution performed as shown in Table 2. As the concentration of ammonium formate was increased, the analytes retained more on the stationary phase, while the concentration of methanol was increased, it reduced the interactions between the analytes and the stationary phase, and consequently decreased the run time. When $0.05 \mathrm{M}$ ammonium formate alone was used as the eluent, the analytes, such as disulfonic acids with $-\mathrm{NO}_{2}$ and $-\mathrm{N}_{3}$ groups, were not eluted. In $100 \%$ methanol, compounds such as monosulfonic acids with $-\mathrm{NH}_{2}$ groups were merged with each other. Thus a gradient program, as shown in Table 2, was chosen for the elution and separation of all the compounds under investigation. It was observed that the elution order of the analytes depends on the functional groups present on the compounds. The mono sulfonic acids with amino $\left(-\mathrm{NH}_{2}\right)$ groups eluted first, followed by disulfonic acids with $-\mathrm{NH}_{2}$ groups, mono sulfonic acids with nitro $\left(-\mathrm{NO}_{2}\right)$ groups, disulfonic acids with both $-\mathrm{NH}_{2}$ and $-\mathrm{NO}_{2}$ groups, disulfonic acids with $-\mathrm{NO}_{2}$ groups and disulfonic acid with $-\mathrm{N}_{3}$ groups. The elution order was found to be the same under two different conditions checked using two different buffers viz., ammonium acetate and ammonium formate with methanol as an organic modifier. The HPLC conditions described in this study are suitable for ESI-MS due to the fact that the ammonium formate does not impair the mass spectrometric analysis. Figure 2 shows the HPLC chromatogram of the test substances. Retention data, including the relative responses of PDA detector and wavelengths of maximum absorption $\left(\lambda_{\max }\right)$, are given Table 3 . It can be seen from Table 3 that the isomeric sulfonates viz., MPDSA, PPDSA, AASA and PPDSAA were well-separated under the

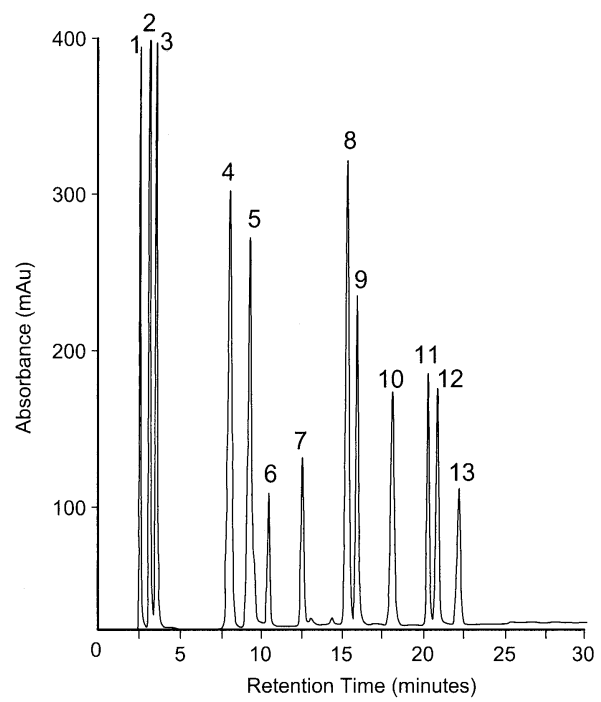

Fig. 2 HPLC chromatogram of synthetic mixture containing 1) PPDDSA, 2) MPDSA, 3) PPDSA, 4) AASA, 5) PPDSAA, 6) DASDSA, 7) PNAOSA, 8) DNBSA, 9) ANSDSA, 10) PNTSA, 11) PAABSA, 12) DNSDSA and 13) BASDSA.

conditions employed in the present study. The separation factors $(\alpha)$ between PPDSA $\left(t_{\mathrm{R}} 2.60 \mathrm{~min}, k^{\prime} 1.19, \lambda_{\max } 219\right)$ and its isomer, MPDSA $\left(t_{\mathrm{R}} 3.08 \mathrm{~min}, k^{\prime} 1.62, \lambda_{\max } 227\right)$, AASA $\left(t_{\mathrm{R}}\right.$ $\left.8.15 \mathrm{~min}, k^{\prime} 4.61, \lambda_{\max } 227\right)$ and its isomer PPDSAA $\left(t_{\mathrm{R}} 9.37\right.$ min, $k^{\prime} 5.49, \lambda_{\max } 257$ ) were determined to be 1.36 and 1.19 , respectively.

The optimized LC conditions were evaluated for a quantitative determination of benzene and stilbene sulfonic acids in water using a PDA detector. Calibration plots of the peak areas versus concentration were obtained for all analytes by a linear regression of at least five data points in the range of $1-500 \mathrm{ng}$ at $254 \mathrm{~nm}$. Calibration plots with correlation coefficients of $R^{2}>0.99$ were obtained. The lower limits of detection (LOD) and quantification (LOQ) were determined at signal to noise ratios of 3.0 and 9.0, respectively, and the results are recorded in Table 4 . The reproducibility of the peak areas checked by four consecutive injections of standard mixture. The peak areas of all analytes showed relative standard deviations in the range of $2.4-3.8 \%$.

Figure 3 shows the total ion current trace of a synthetic mixture containing the benzene and stilbene sulfonates under study. It can be seen from Fig. 3 that all of the compounds were efficiently transformed into $\left[\mathrm{M}-\mathrm{H}^{+}\right]^{-}$ions under the ionization conditions employed in this study. Further, it may be noted that that the $\left[\mathrm{M}-\mathrm{H}^{+}\right]^{-}$ion is the diagnostic peak for benzene sulfonic acids, while $\left[\mathrm{M}-\mathrm{H}^{+}\right]^{-}$and $\left[(\mathrm{M} / 2)-\mathrm{H}^{+}\right]^{-}$are diagnostic peaks for stilbene sulfonic acids, except for ANSDSA, in which case only $\mathrm{m} / \mathrm{z}, 399$ corresponding to $\left[\mathrm{M}-\mathrm{H}^{+}\right]^{-}$was observed. Isomers of benzene sulfonates i) PPDSA/MPDSA of $\left[\mathrm{M}-\mathrm{H}^{+}\right]^{-} 187$ and ii) AASA/PPDSAA of $\left[\mathrm{M}-\mathrm{H}^{+}\right]^{-} 229$ were identified from the retention as well as UV absorption data. The fragment ions along with their relative abundance are recorded in Table 5. Figure 4 shows the typical mass spectrum of bis azido stilbene disulfonic acid characterized by 421, 393, 365, 210, 182 and 80, corresponding to the $\left[\mathrm{M}-\mathrm{H}^{+}\right]^{-},\left[\mathrm{M}-\mathrm{H}^{+}-\mathrm{N}_{2}\right]^{-},\left[\mathrm{M}-\mathrm{H}^{+}-2 \mathrm{~N}_{2}\right]^{-}$, $\left[(\mathrm{M} / 2)-\mathrm{H}^{+}\right]^{-},\left[(\mathrm{M} / 2)-\mathrm{H}^{+}-\mathrm{N}_{2}\right]^{-}$and $\mathrm{SO}_{3}{ }^{-}$ions, respectively.

The proposed method was successfully adopted to determine the levels of aromatic sulfonates in different industrial wastewater effluents. An effluent sample obtained from industry was analyzed, and the total amount of sulfonates was found to be 
Table 4 Linearity, limits of detection and quantification data

\begin{tabular}{cccccc}
\hline Compound No. & Linear range/ng & Calibration data & $r^{2}$ & LOD/ng & LOQ/ng \\
\hline 1 & $1-500$ & $Y=42465 X-2588$ & 0.9999 & 0.19 & 0.57 \\
2 & $1-500$ & $Y=63604 X+145$ & 0.9999 & 0.16 & 0.48 \\
3 & $1-500$ & $Y=56058 X+43$ & 0.9999 & 0.18 & 0.54 \\
4 & $1-500$ & $Y=730404 X+1480$ & 0.9999 & 0.24 & 0.72 \\
5 & $1-500$ & $Y=59309 X+1648$ & 0.9994 & 0.26 & 0.78 \\
6 & $10-500$ & $Y=16122 X-1889$ & 0.9996 & 1.83 & 5.49 \\
7 & $2-500$ & $Y=18416 X+1981$ & 0.9999 & 0.43 & 1.29 \\
9 & $1-500$ & $Y=52784 X+1274$ & 0.9999 & 0.22 & 0.66 \\
10 & $1-500$ & $Y=36236 X+2643$ & 0.9997 & 0.21 & 0.63 \\
11 & $5-500$ & $Y=19309 X-2715$ & 0.9999 & 0.82 & 2.46 \\
13 & $1-500$ & $Y=28009 X+3198$ & 0.9999 & 0.22 & 0.66 \\
\end{tabular}

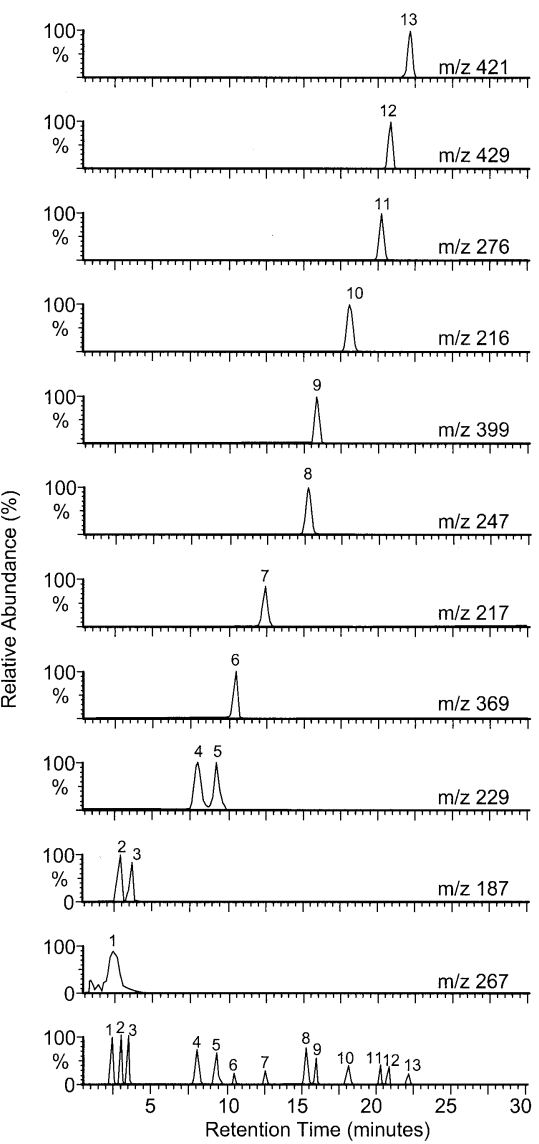

Fig. 3 TIC chromatogram of benzene and stilbene sulfonic acids.

maximum of $0.05 \%$. From these results, it could be seen that the present work provides a comprehensive procedure for monitoring industrial pollutants, such as aromatic sulfonates in aquatic environment using LC with PDA and ESI-MS as detectors.

\section{Acknowledgements}

The authors wish to thank Dr. K. V. Raghavan, Director, IICT for encouragement and permission to communicate the results for publication (IICT communication No. 020901).
Table 5 ESI-MS data and assignments

\begin{tabular}{|c|c|c|c|}
\hline Sulfonate & $m / z$ & $\begin{array}{c}\text { Mass data }(\mathrm{m} / \mathrm{z}) \\
\text { with relative } \\
\text { abundance }\end{array}$ & Assignment \\
\hline PPDDSA & 268 & $267(100)$ & {$\left[\mathrm{M}-\mathrm{H}^{+}\right]^{-}$} \\
\hline \multirow[t]{2}{*}{ MPDSA } & 188 & $187(100)$ & {$\left[\mathrm{M}-\mathrm{H}^{+}\right]^{-}$} \\
\hline & & $91(30)$ & {$\left[\mathrm{M}-\mathrm{H}^{+}-\mathrm{SO}_{3}-\mathrm{NH}_{2}\right]^{-}$} \\
\hline PPDSA & 188 & $187(100)$ & {$\left[\mathrm{M}-\mathrm{H}^{+}\right]^{-}$} \\
\hline AASA & 230 & $229(100)$ & {$\left[\mathrm{M}-\mathrm{H}^{+}\right]^{-}$} \\
\hline \multirow[t]{2}{*}{ PPDSAA } & 230 & $229(55)$ & {$\left[\mathrm{M}-\mathrm{H}^{+}\right]^{-}$} \\
\hline & & $106(100)$ & {$\left[\mathrm{M}-\mathrm{H}^{+}-\mathrm{SO}_{3}-\mathrm{COCH}_{3}\right]^{-}$} \\
\hline \multirow[t]{5}{*}{ DASDSA } & 370 & $369(20)$ & {$\left[\mathrm{M}-\mathrm{H}^{+}\right]^{-}$} \\
\hline & & $184(17)$ & {$\left[(\mathrm{M} / 2)-\mathrm{H}^{+}\right]^{-}$} \\
\hline & & $75(100)$ & {$\left[(\mathrm{M} / 2)-\mathrm{H}^{+}-\mathrm{SO}_{3}-\mathrm{NH}_{2}-\mathrm{CH}\right]^{-}$} \\
\hline & & $89(68)$ & {$\left[(\mathrm{M} / 2)-\mathrm{H}^{+}-\mathrm{SO}_{3}-\mathrm{NH}\right]^{-}$} \\
\hline & & $91(40)$ & {$\left[(\mathrm{M} / 2)-\mathrm{H}^{+}-\mathrm{SO}_{3}-\mathrm{CH}\right]^{-}$} \\
\hline \multirow[t]{4}{*}{ PNAOSA } & 218 & $217(52)$ & {$\left[\mathrm{M}-\mathrm{H}^{+}\right]^{-}$} \\
\hline & & $75(100)$ & {$\left[\mathrm{M}-\mathrm{H}^{+}-\mathrm{SO}_{3}-\mathrm{NO}_{2}-\mathrm{NH}_{2}\right]^{-}$} \\
\hline & & $89(68)$ & {$\left[\mathrm{M}-\mathrm{H}^{+}-\mathrm{SO}_{3}-\mathrm{NH}_{2}-\mathrm{O}_{2}\right]^{-}$} \\
\hline & & $91(40)$ & {$\left[\mathrm{M}-\mathrm{H}^{+}-\mathrm{SO}_{3}-\mathrm{NO}-\mathrm{NH}_{2}\right]^{-}$} \\
\hline DNBSA & 248 & $247(100)$ & {$\left[\mathrm{M}-\mathrm{H}^{+}\right]^{-}$} \\
\hline ANSDSA & 400 & $399(100)$ & {$\left[\mathrm{M}-\mathrm{H}^{+}\right]^{-}$} \\
\hline PNTSA & 217 & $216(100)$ & {$\left[\mathrm{M}-\mathrm{H}^{+}\right]^{-}$} \\
\hline PAABSA & 277 & $276(100)$ & {$\left[\mathrm{M}-\mathrm{H}^{+}\right]^{-}$} \\
\hline \multirow[t]{2}{*}{ DNSDSA } & 430 & $429(22)$ & {$\left[\mathrm{M}-\mathrm{H}^{+}\right]^{-}$} \\
\hline & & $214(100)$ & {$\left[(\mathrm{M} / 2)-\mathrm{H}^{+}\right]^{-}$} \\
\hline \multirow[t]{6}{*}{ BASDSA } & 422 & $421(48)$ & {$\left[\mathrm{M}-\mathrm{H}^{+}\right]^{-}$} \\
\hline & & 393 (10) & {$\left[\mathrm{M}-\mathrm{H}^{+}-\mathrm{N}_{2}\right]^{-}$} \\
\hline & & $365(10)$ & {$\left[\mathrm{M}-\mathrm{H}^{+}-2 \mathrm{~N}_{2}\right]^{-}$} \\
\hline & & $210(10)$ & {$\left[(\mathrm{M} / 2)-\mathrm{H}^{+}\right]^{-}$} \\
\hline & & $82(40$ & {$\left[(\mathrm{M} / 2)-\mathrm{H}^{+}-\mathrm{N}_{2}\right]^{-}$} \\
\hline & & $80(100)$ & {$\left[\mathrm{SO}_{3}\right]^{-}$} \\
\hline
\end{tabular}

\section{References}

1. P. S. Tully, in "Kirk-Othmer Encyclopedia of Chemical Technology", ed. M. H. Grant, 4th ed., 1997, Vol. 23, John Wiley \& Sons, New York, $194-217$.

2. M. A. Hashm, J. Kulandai, and R. S. Hassan, J. Chem. Technol. Biotechnol., 1992, 54, 207.

3. R. A. Gimeno, J. L. Beltran, R. M. Marce, and F. Borrull, J. Chromatogr. A, 2000, 890, 289.

4. A. Preiss, U. Sanger, M. Kartich, K. Levsen, and C. Mugge, Anal. Chem., 2000, 72, 992.

5. C. Wolf, T. Storm, F. T. Lange, T. Reemtsma, H. J. Brauch, S. H. Eberle, and M. Jekel, Anal. Chem., 2000, 72, 


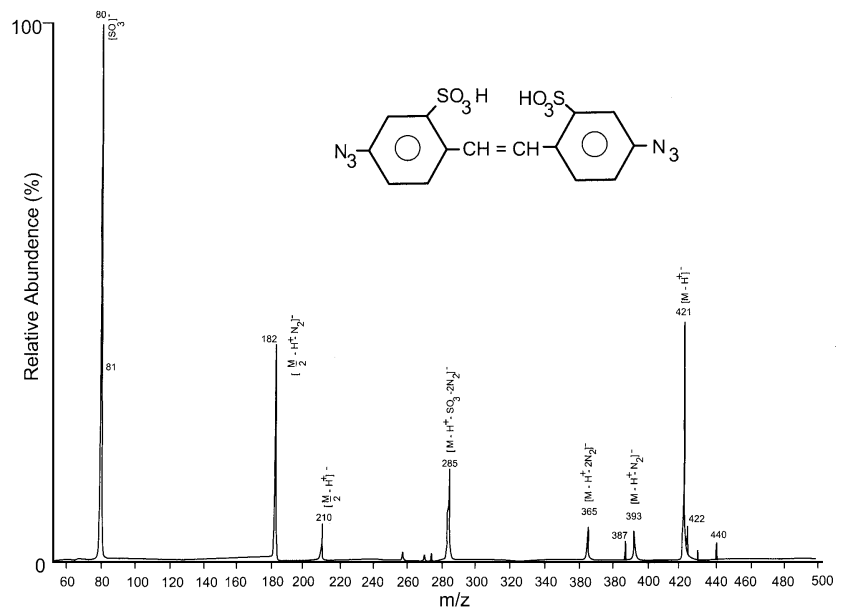

Fig. 4 LC-ESI-MS spectra of BASDSA with assignment of fragments.

5466.

6. M. J. Cugat, F. Borull, and M. Calull, Analyst, 2000, 125 , 2236.
7. A. Amer, E. G. Alley, and C. U. Pittman, J. Chromatogr., 1986, 362, 413 .

8. M. Nakada, A. Uzawa, and M. Hirota, Nippon Kagaku Kaishi, 1984, 5, 728 .

9. R. Loos and R. Niessner, J. Chromatogr. A, 1998, 822, 291.

10. M. J. Cugat, F. Borull, and M. Calull, Tre. Anal. Chem., 2001, 20, 487.

11. I. Kim, F. Sasinos, K. Rishi, R. Stephens, and M. Brown, J. Chromatogr., 1991, 589, 177

12. G. Socher, R. Nussbaum, K. Rissler, and E. Lankmayr, J. Chromatogr. A, 2001, 912, 53.

13. M. C. Alanso M. Castillo, and D. Barcelo, Anal. Chem., 1999, 71, 2586.

14. B. Altenbach and W. Giger, Anal. Chem., 1995, 67, 2325.

15. O. Zerbinati and G. Ostacoli, J. Chromatogr. A, 1994, 671, 217.

16. T. Storm, T. Reemtsma, and M. Jekel, J. Chromatogr. A, 1999, 854, 175.

17. R. E. A. Escott and D. W. Chandler, J. Chromatogr. Sci., 1989, 27, 134.

18. D. R. Wilder, G. W. Tindall, L. J. Cunningham, and J. L. Little, J. Chromatogr., 1993, 635, 221. 